\title{
Photoprotective effect and acute oral systemic toxicity evaluation of the novel heterocyclic compound LQFM048
}

\author{
Daniela C. Vinhal ${ }^{\mathrm{a}}$, Renato Ivan de Ávila ${ }^{\mathrm{b}}$, Marcelo S. Vieira ${ }^{\mathrm{b}}$, Rangel M. Luzin ${ }^{\mathrm{c}}$, Michelle P. Quintino ${ }^{\mathrm{c}}$, \\ Liliane M. Nunes ${ }^{\mathrm{d}}$, Antonio Carlos Chaves Ribeiro ${ }^{\mathrm{d}}$, Henrique Santiago de Camargo ${ }^{\mathrm{d}}$, Angelo C. Pinto ${ }^{\mathrm{e}}$, \\ Helvécio M. dos Santos Júnior ${ }^{\mathrm{e}}$, Bruna G. Chiari ${ }^{\mathrm{f}}$, Vera Isaac ${ }^{\mathrm{f}}$, Marize C. Valadares ${ }^{\mathrm{b}, *}$, Tatiana Duque Martins ${ }^{\mathrm{d}}$, \\ Luciano M. Lião ${ }^{\mathrm{C}}$, Eric de S. Gil ${ }^{\mathrm{e}}$, Ricardo Menegatti ${ }^{\mathrm{a}, *}$ \\ a Laboratório de Química Farmacêutica Medicinal (LQFM), Faculdade de Farmácia, Universidade Federal de Goiás, Goiânia, GO, Brazil \\ b Laboratório de Farmacologia e Toxicologia Celular, LFTC/FarmaTec, Faculdade de Farmácia, Universidade Federal de Goiás, Goiânia, GO, Brazil \\ c Laboratório de Ressonância Magnética Nuclear, Instituto de Química, Universidade Federal de Goiás, Goiânia, GO, Brazil \\ ' Instituto de Ouímica, Universidade Federal de Goiás, Goiânia, GO, Brazil \\ e Laboratório de Espectrometria de Massas, LABEM, Universidade Federal do Rio de Janeiro, Rio de Janeiro, RJ, Brazil \\ ${ }^{\mathrm{f}}$ Laboratório de Cosmetologia, LaCos, Departamento de Fármacos e Medicamentos, Faculdade de Ciências Farmacêuticas, Universidade Estadual Paulista Júlio de Mesquita Filho, \\ Araraquara, SP, Brazil
}

\section{A R T I C L E I N F O}

\section{Article history:}

Received 10 December 2015

Received in revised form 17 March 2016

Accepted 29 March 2016

Available online 2 April 2016

\section{Keywords:}

Heterocyclic derivative

Molecular hybridization

Photoprotection

Sunscreen

Green chemistry

\begin{abstract}
A B S T R A C T
The new heterocyclic derivative LQFM048 (3) (2,4,6-tris ((E)-ethyl 2-cyano-3-(4-hydroxy-3methoxyphenyl)acrylate)-1,3,5-triazine) was originally designed through the molecular hybridization strategy from Uvinul ${ }^{\circledR}$ T 150 (1) and (E)-ethyl 2-cyano-3-(4hydroxy-3-methoxyphenyl)acrylate (2) sunscreens, using green chemistry approach. This compound was obtained in global yields (80\%) and showed an interesting redox potential. In addition, it is thermally stable up to temperatures around $250{ }^{\circ} \mathrm{C}$. It was observed that LQFM048 (3) showed a low degradation after $150 \mathrm{~min}$ of sunlight exposure at $39^{\circ} \mathrm{C}$, whereas the extreme radiation conditions induced a considerable photodegradation of the LQFM048 (3), especially when irradiated by VIS and VIS + UVA. During the determination of sun protection factor, LQFM048 (3) showed interesting results, specially as in association with other photoprotective compounds and commercial sunscreen. Additionally, the compound (3) did not promote cytotoxicity for 3T3 fibroblasts. Moreover, it was not able to trigger acute oral systemic toxicity in mice, being classified as a compound with low acute toxicity hazard $\left(2.000 \mathrm{mg} / \mathrm{kg}>\mathrm{LD}_{50}<5.000 \mathrm{mg} / \mathrm{kg}\right)$. Therefore, this compound synthesized using green chemistry approach is promising showing potential to development of a new sunscreen product with advantage of presenting redox potential, indicating antioxidant properties.
\end{abstract}

(C) 2016 Elsevier B.V. All rights reserved.

\section{Introduction}

Excessive exposure to solar ultraviolet radiation (UV) of humans has increased due to the depletion of the ozone layer and changes in outdoor lifestyle [1]. Moreover, outdoor workers are also daily exposed to UV [2]. Solar UV rays that reach the Earth's surface are divided into two main bands named of UVB (290-320 nm) and UVA (320-400 nm) [3].

In the skin, both bands induce DNA damage by different mechanisms: UVB directly damages the DNA promoting the formation of the 6-4 cyclobutane pyrimidine dimmers [3-5] and UVA radiation can promote oxidative damage by overproduction of reactive oxygen species (ROS)

\footnotetext{
* Corresponding authors at: Faculdade de Farmácia, Universidade Federal de Goiás, Rua 240 Esquina com $5^{\text {a }}$ Avenida, s/n, Setor Universitário, Goiânia, GO CEP: 74605.170. Brazil. E-mail addresses: marizeufg@gmail.com (M.C. Valadares),rm_rj@yahoo.com (R. Menegatti).
}

that injure DNA molecules [4,6]. Consequently, solar UV-spectrum can promote short and long term harmful clinical consequences such as sunburns, premature skin aging and even suppression of specific immune responses and skin cancer [7-9]. Also, this scenario brings in a large cost on health care [10], especially in tropical countries. In this context, sun-related protection measures are encouraged such as the development and use of sunscreen products.

Sunscreens are classified as inorganic or organic based on its composition [11]. The first class is composed by mineral particles such as $\mathrm{TiO}_{2}$ and $\mathrm{ZnO}$ that reflect or scatter UV rays from the skin, while organic filters absorb UV light and transform it into vibrational, fluorescence and radical energy due to its aromatic structures [11-13].

In sunscreen formulations, a combination of these types of filters is widely employed to provide broad-spectrum protection [14]. However, this combination can present limitations such as photostability and photoactivity of some organic and inorganic filters, respectively. Recently, the improvement of sunscreens' raw materials has been done in an 
attempt to solve this problem. Some new raw materials have been launched on the market, such as Uvinul ${ }^{\circledR}$ T 150 (1), a water-resistant compound widely used for UVB protection [15]. Although most of these new materials ensure effective sun-blocking products, there is a need to produce them in a clean and sustainable manner using, for example, small amounts of organic solvents in organic synthesis steps.

In this context, the present study investigated the photoprotective and toxicological evaluation of the new heterocyclic derivative LQFM048 (3) (2,4,6-tris ((E)-ethyl 2-cyano-3-(4-hydroxy-3-methoxyphenyl)acrylate) -1,3,5-triazine), which was originally designed through the molecular hybridization strategy from Uvinul ${ }^{\circledR} \mathrm{T} 150(\mathbf{1})$ and $(E)$-ethyl 2-cyano-3(4hydroxy-3-methoxyphenyl)acrylate (2) sunscreens, using green chemistry approach.

\section{Materials and Methods}

\subsection{Chemicals}

Dulbecco's modified Eagle's medium (DMEM), penicillin, streptomycin, DPPH, trypsin, EDTA, chloroform, acetronitrile, toluene, tetramethylsilane (TMS), phosphoric acid, formic acid and in vitro toxicology assay kit (lactic dehydrogenase based) were purchased from Sigma-Aldrich (St. Louis, MO, USA). Tetrahydrofuran (THF) was acquired from Tedia Brazil (Rio de Janeiro, RJ, Brazil). Deuterated chloroform $\left(\mathrm{CDCl}_{3}\right)$ was purchased from Cambridge Isotope Laboratories Inc. (Tewksbury, MA, USA) while ethyl cyanoacetate, 2,4,6-trichloro-1,3,5triazine and morpholine from Acros Organics (Geel, Belgium). Methanol, dichloromethane, ethyl acetate, dichloromethane, $n$-hexane, ethanol, DMSO, chloroform, acetic acid, hydrochloric acid $(\mathrm{HCl})$, sodium chloride $(\mathrm{NaCl})$ and calcium chloride $\left(\mathrm{CaCl}_{2}\right)$ were acquired from Vetec (Rio de Janeiro, RJ, Brazil) while ethylhexyl methoxycinnamate, silica gel 760 and vanillin from Merck (Darmstadt, HE, Germany). Tinosorb® S was acquired from BASF (Ludwigshafen, Germany). Xylazine and ketamine were purchased from Syntec (Cotia, SP, Brazil) and König (Santana de Parnaíba, SP, Brazil), respectively. Sunflower oil and potassium carbonate $\left(\mathrm{K}_{2} \mathrm{CO}_{3}\right)$ were purchased from Liza (PR, Brazil) and Synth (SP, Brazil), respectively. Graphite was acquired from Metrohm Autolab B.V. (Kanaalweg, Utrecht, The Netherlands) and mineral oil was purchased from Biolub Chemistry LTDA (Sorocaba, SP, Brazil).

\subsection{General}

${ }^{1} \mathrm{H}$, and ${ }^{13} \mathrm{C}$ NMR measurements were carried out on a Bruker Avance III 500 instrument (operating at $500.13 \mathrm{MHz}$ for $1 \mathrm{H}$ ) equipped with a $5 \mathrm{~mm}$ tuneable multinuclear triple (TBI) resonance probe head equipped with $\mathrm{z}$ gradient. To acquire ${ }^{1} \mathrm{H}$ and ${ }^{13} \mathrm{C}$ experiments, samples containing $20 \mathrm{mg}$ of LQFM 048 (3) in $\mathrm{CDCl}_{3}$ and $1 \%$ tetramethylsilane as internal standard were used. Following 1D and 2D pulse sequences from the Bruker user library were used for the NMR experiments.

High-resolution mass spectrometry analyses were performed on a QTOF Micro (Waters, Manchester, UK) mass spectrometer equipped with an ESI source. The analyses were recorded between $\mathrm{m} / \mathrm{z} 90$ and 1000 in positive ion mode, and the mass spectrometer parameters were: nebulization gas was set to $500 \mathrm{~L} / \mathrm{h}$ at $140{ }^{\circ} \mathrm{C}$, cone gas set to $50 \mathrm{~L} / \mathrm{h}$, and source temperature set to $100^{\circ} \mathrm{C}$. Capillary and cone voltage were set to $4500 \mathrm{~V}$ and $25 \mathrm{~V}$, respectively. QTOF acquisition rate was set to $1.0 \mathrm{~s}$, with a $0.4 \mathrm{~s}$ inter-scan delay and the data processed on MassLynx 4.0 software (Waters, Manchester, UK). Analytes were acquired using LockSpray and phosphoric acid (0.1\% in acetonitrile/ water, 1:1) as internal standard to ensure accuracy mass. The sample solutions $(0.5 \mathrm{mg} / \mathrm{mL})$ were prepared in acetonitrile with addition of $20 \mu \mathrm{L}$ of formic acid. The analyses were carried out by direct infusion using a syringe pump at $5.0 \mu \mathrm{L} / \mathrm{min}$ flow ratio.

Infrared spectra were obtained with a Nicolet-55a Magna spectrophotometer (GMI, MN, USA) using potassium bromide plates.
The progress of all reactions was monitored by thin-layer chromatography (TLC), which was performed on $2.0-6.0 \mathrm{~cm}$ aluminum sheets precoated with silica gel 760 to a thickness of $0.25 \mathrm{~mm}$. The chromatograms developed were viewed under ultraviolet light (254-265 nm) and treated with iodine vapor.

\subsection{Synthesis of (E)-Ethyl 2-Cyano-3-(4hydroxy-3-Methoxyphenyl) Acrylate (2)}

Vanillin (4) and ethyl cyanoacetate (5) (both at $3.30 \mathrm{mmol}$ ) in $5 \mathrm{~mL}$ of water were added to a round-bottomed flask under agitation at room temperature. Five mol\% of morpholine was added to this suspension, and the reaction was monitored using TLC. After that, the reaction mixture was partitioned between dichloromethane and water. The organic layer was separated and submitted to the usual workup to furnish a crude precipitate, which was used without rather purification. The derivative (2) was obtained as a yellow solid, yield $98 \%, \mathrm{mp} 108{ }^{\circ} \mathrm{C}$, $\mathrm{Rf}=0.64 n$-hexane:ethyl acetate $(7: 3, v / \mathrm{v})$; IR $\max (\mathrm{KBr}) \mathrm{cm}^{-1}$ : $3375,2219,1702,762 ; \mathrm{RMN}^{1} \mathrm{H}(500 \mathrm{MHz}) \mathrm{CDCl}_{3} / \mathrm{TMS}(\delta): 8.13(1 \mathrm{H}$, s, H-3), $7.82\left(1 \mathrm{H}, \mathrm{d}, J=2.1 \mathrm{~Hz}, \mathrm{H}-2^{\prime}\right), 7.38(1 \mathrm{H}, \mathrm{dd}, J=2.1$ and $8.3 \mathrm{~Hz}$, $\left.\mathrm{H}-6^{\prime}\right), 6.98\left(1 \mathrm{H}, \mathrm{d}, J=8.3 \mathrm{~Hz}, \mathrm{H}-5^{\prime}\right), 4.36\left(2 \mathrm{H}, \mathrm{q}, J=7.1 \mathrm{~Hz}, \mathrm{CH}_{2}\right), 3.96$ $\left(3 \mathrm{H}, \mathrm{s}, \mathrm{OCH}_{3}\right), 1.38\left(3 \mathrm{H}, \mathrm{t}, J=7.2 \mathrm{~Hz}, \mathrm{CH}_{3}\right) ;{ }^{13} \mathrm{C}(125 \mathrm{MHz}) \mathrm{CDCl}_{3} / \mathrm{TMS}$

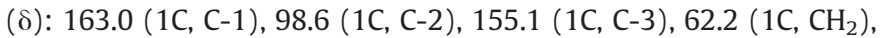
14.0 (1C, $\left.\mathrm{CH}_{3}\right), 116.4(1 \mathrm{C}, \mathrm{CN}), 56.0\left(1 \mathrm{C}, \mathrm{OCH}_{3}\right), 151.1$ (1C, C-1'), 111.3 (1C, C-2'), 147.0 (1C, C-3'), 124.0 (1C, C-4'), 115.0 (1C, C-5'), 128.6 $\left(1 \mathrm{C}, \mathrm{C}-6^{\prime}\right) ;[\mathrm{M}+\mathrm{H}]^{+}=247.07608$.

2.4. 4.4. Synthesis of (2,4,6-Tris ((E)-Ethyl 2-Cyano-3-(4-Hydroxy-3Methoxyphenyl) Acrylate)-1,3,5-Triazine) (3)

(E)-ethyl 2-cyano-3-(4hydroxy-3-methoxyphenyl)acrylate (2) (3.50 mmol), $\mathrm{K}_{2} \mathrm{CO}_{3}$ (3.50 mmol) and 2,4,6-trichloro-1,3,5-triazine (6) (10 mmol) in $50 \mathrm{~mL}$ of 1,2-dichloroethane were added to a $100 \mathrm{~mL}$ round-bottomed flask under agitation at room temperature. The mixture was stirred at $80^{\circ} \mathrm{C}$ for $6 \mathrm{~h}$. At the end of the reaction, the solvent was removed in vacuo and the reaction mixture was partitioned between dichloromethane and water. The organic layer was separated and submitted to the usual workup to furnish a crude precipitate, which was purified by Soxhlet extraction with acetonitrile for eight hours. LQFM048 (3) was obtained as a beige solid, yield $80 \%, \mathrm{mp}$ $186{ }^{\circ} \mathrm{C}, \mathrm{Rf}=0.92 \mathrm{CH}_{2} \mathrm{Cl}_{2}: \mathrm{MeOH}(95: 5, v / \mathrm{v})$; IR $\max (\mathrm{KBr}) \mathrm{cm}^{-1}: 3100$, 2216, 1720; $\mathrm{RMN}^{1} \mathrm{H}(500 \mathrm{MHz}) \mathrm{CDCl}_{3} / \mathrm{TMS}(\delta): 8.16$ (1H, s, H-3), 7.71 $\left(1 \mathrm{H}, \mathrm{d}, J=1.9 \mathrm{~Hz}, \mathrm{H}-2^{\prime}\right), 7.42\left(1 \mathrm{H}, \mathrm{dd}, J=1.9\right.$ and $\left.8.4 \mathrm{~Hz}, \mathrm{H}-6^{\prime}\right), 7.18$ $\left(1 \mathrm{H}, \mathrm{d}, J=8.4 \mathrm{~Hz}, \mathrm{H}-5^{\prime}\right), 4.40\left(2 \mathrm{H}, \mathrm{q}, J=7.2 \mathrm{~Hz}, \mathrm{CH}_{2}\right), 3.82(3 \mathrm{H}, \mathrm{s}$, $\left.\mathrm{OCH}_{3}\right), 1.42\left(3 \mathrm{H}, \mathrm{t}, J=7.2 \mathrm{~Hz}, \mathrm{CH}_{3}\right) ;{ }^{13} \mathrm{C}(125 \mathrm{MHz}) \mathrm{CDCl}_{3} / \mathrm{TMS}(\delta)$ : 162.1 (1C, C-1), 102.9 (1C, C-2), 153.9 (1C, C-3), 62.6 (1C, $\left.\mathrm{CH}_{2}\right), 14.0$ $\left(1 \mathrm{C}, \mathrm{CH}_{3}\right), 113.1(1 \mathrm{C}, \mathrm{CN}), 56.0\left(1 \mathrm{C}, \mathrm{OCH}_{3}\right), 153.7\left(1 \mathrm{C}, \mathrm{C}-1^{\prime}\right), 113.2(1 \mathrm{C}$, C-2'), 151.3 (1C, C-3'), 130.0 (1C, C-4'), 123.0 (1C, C-5'), 125.5 (1C, C$\left.6^{\prime}\right), 173.0\left(1 \mathrm{C}, \mathrm{C}-1^{\prime \prime}, 3^{\prime \prime}\right.$ and $\left.5^{\prime \prime}\right) ;[\mathrm{M}+\mathrm{H}]^{+}=817.77560$.

\subsection{Determination of the Antioxidant Potential of LQFM048 (3)}

\subsubsection{2,2-Diphenyl-1-Picrylhydrazyl (DPPH•) Free Radical}

The free radical scavenging capacity of LQFM048 (3) was determined with $\mathrm{DPPH} \bullet$ as previously described [16]. LQFM048 (3) solutions $(50 \mu \mathrm{L})$ in different concentrations $(2,4,8,15,31,61.3,122.5$ or $245 \mu \mathrm{M})$ were added to $150 \mu \mathrm{L}$ of DPPH solution $(0.3 \mathrm{mM})$, both diluted in $95 \%$ methanol, and incubated in the dark. After $30 \mathrm{~min}$, absorbance was obtained using a spectrophotometer (Thermo Scientific Multiskan ${ }^{\circledR}$ Spectrum, MA, USA) at $517 \mathrm{~nm}$.

\subsubsection{Cyclic Voltammetry}

All electrochemical measurements were performed with a $\mu$ Autolab Type III ${ }^{\circledR}$ potentiostat/galvanostat (Eco-ChemieB.V., Utrecht, The Netherlands) coupled to GPES version 4.3 software for data acquisition, connected to a system of electrochemical cell with three electrodes, 
namely a modified carbon paste working electrode, a calomel reference electrode and a platinum wire counter electrode.

The electroanalytical assays were performed by solid state voltammetry by modifying the carbon paste electrode with the analyte samples in $\mathrm{pH} 7.0,0.1 \mathrm{M}$ phosphate buffer at $100 \mathrm{mV} \mathrm{s}^{-1}$, from -0.25 to $1.25 \mathrm{~V}$. The $\mathrm{pH}$ measurements were carried out on a $\mathrm{pH}$ meter, from Logen LSPHS 25CW, brand model with a universal glass electrode trademark Eltex.

Taking into account the scarce water solubility of $(E)$-ethyl 2cyano-3-(4-hydroxy-3-methoxyphenyl)acrylate (2) and LQFM048 (3), their electrochemical characterizations were performed at solid state. Thus, $5 \mathrm{mg}$ of compound (2) were dispersed in $20 \mathrm{mg}$ of mineral oil and then the resulting homogenous dispersion was mixed for $15 \mathrm{~min}$ with $60 \mathrm{mg}$ of graphite, leading to Modified Carbon Paste Electrode (MCP)-1. The same procedure was applied for ethylhexyl methoxycinnamate, in order to obtain the modified carbon paste, MCP-2.

\subsection{Thermogravimetric Analysis of LQFM048 (3)}

Thermal stability was available using a DTG-60H thermobalance (Shimadzu, MD, USA), with samples of about $4.0 \mathrm{mg}$ of LQFM048 (3), which were heated under synthetic air atmosphere from 30 to $600{ }^{\circ} \mathrm{C}$, at a flow rate of $50 \mathrm{~mL} \mathrm{~min}^{-1}$ and a heating rate of $10{ }^{\circ} \mathrm{C} / \mathrm{min}$.

\subsection{Photostability Analysis of LQFM048 (3)}

\subsubsection{Photostability Uponsunexposure}

For photostalibity evaluation under natural sunlight, a solution of LQFM048 (3) $(18.3 \mu \mathrm{M})$ dissolved in DMSO was divided within two glass Petri dishes $(60 \mathrm{~mm})$ with no cover for direct sun radiation exposure. One of these dishes with LQFM048 (3) solution and another one with vehicle only (DMSO) were kept protected from radiation by aluminum foil. All dishes were kept under the same conditions. During the experiment, the temperature was monitored at $39 \pm 2{ }^{\circ} \mathrm{C}$. The radiation from sunlight was $27 \pm 2 \mathrm{~W} \cdot \mathrm{h} / \mathrm{m}^{2}$, measured at intervals of $10 \mathrm{~min}$ using a radiometer (model 732, CHY firemate CO., Taiwan). Time exposure and radiation dose were $150 \mathrm{~min}$ and $54.2 \mathrm{~W} \cdot \mathrm{h} / \mathrm{m}^{2}$, respectively. The assay was performed in Goiânia, GO, Brazil ( $-16^{\circ} 40^{\prime} 41.04^{\prime \prime}$; $\left.-49^{\circ} 14^{\prime} 34.79^{\prime \prime}\right)$, autumn season. The exposure was at maximum sun radiation from 11:20 h a.m. to 01:30 p.m. After time exposure, absorbance was measured using spectrophotometer at 250-400 nm. The area under the curve (AUC) was calculated as previously described [17].

\subsubsection{Photostability Upon Irradiation by UV and VIS Lamps}

The investigation of photostability of LQFM048 (3) after exposure to UVA and VIS light was performed as described by the International Conference on Harmonization of Technical Requirements for Registration of Pharmaceuticals for Human Use [18] using a 6545 series photostability chamber (Caron, OH, USA). This chamber was made to meet specifically some legislation requirements, such as European Medicines Agency, U.S. Food and Drug Administration and Brazilian Sanitary Surveillance Agency (ANVISA), for photostability assay according to ICH Q1B option II.

LQFM048 (3) dissolved in DMSO was divided within 8 crimped vials and exposed to 1.2 million lux.h of VIS light and $200 \mathrm{~W} \cdot \mathrm{h} / \mathrm{m}^{2}$ of UVA radiation. The time needed to reach the VIS dosage was $40 \mathrm{~h}$ and $8 \mathrm{~h}$ for UV radiation, under $25^{\circ} \mathrm{C}$. The exposures were: 2 vials under only UVA radiation (UVA); 2 vials under only VIS light (VIS); 2 vials exposed to both first to VIS light and after to UVA radiation (VIS + UVA) and 2 vials with vehicle control (DMSO) under the same conditions until the end of the experiment. All conditions of radiation exposures had the same sample protected from radiation by aluminum foil kept inside the photostability chamber. After time exposure, absorbance was measured using a spectrophotometer at $250-400 \mathrm{~nm}$ and AUC was calculated.

\subsection{Photophysical Characterization}

Photophysical behavior of LQFM048 (3) was investigated by steady-state fluorescence spectroscopy of its diluted solutions prepared in distinct solvents, such as tetrahydrofuran (THF), chloroform, acetonitrile and toluene. Steady-state excitation and fluorescence spectra were recorded in a Fluorolog 3-221 Horiba Jobin Yvon spectrophotometer, with a $450 \mathrm{~W}$ Xe arc-lamp, connected to a double monochromator, polarization system in the entrance and a sample holder to contain a $1 \mathrm{~cm}$-quartz cuvette of optical path. Emission was detected at $90^{\circ}$ with respect to the incident radiation by a Hamamatsu photomultiplier, operating at the range of 250 to $850 \mathrm{~nm}$. Narrow slits were employed to guarantee the resolution of $1.0 \mathrm{~nm}$ to the measurements.

\subsection{Evaluation of Sun Protection Factor (SPF) of LQFM048 (3)}

The SPF value of LQFM048 (3) was determined through two in vitro methods. The first one was carried out as described by Mansur et al. [19]. Briefly, LQFM048 (3) solution $\left(1.2 \times 10^{-5} \mathrm{M}\right)$ was prepared using chloroform as solvent. To determine the SPF value promoted by LQFM048 (3), absorbance was measured using a spectrophotometer at $290,295,300,305,310,315$ and $320 \mathrm{~nm}$.

The second methodology used the equipment Optometrics SPF-290S analyzer (Laser Components, Olching, Germany), following the manufacturer's instruction. Thus, $110 \mathrm{mg}$ of a solution of LQFM048 (3) dissolved in chloroform $(1: 1, w / v)$ was applied to the Transpore ${ }^{\mathrm{TM}}$ tape ( $3 \mathrm{M}$, MN, USA) $(70.7 \times 70.7 \mathrm{~mm})$ to obtain a sample film of $2 \mu \mathrm{g} / \mathrm{cm}^{2}$, as specified by the U.S. Food and Drug Administration [20]. The membrane containing the sample was exposed to xenon arc solar simulator, which performed 12 scans of each sample in different locations on the Transpore ${ }^{\mathrm{TM}}$ tape substrate. Each scan takes a transmittance measurement every $2 \mathrm{~nm}$ from 290 to $400 \mathrm{~nm}$, enabling the assessment of SPF by the equipment.

These procedures were repeated using a commercial sunscreen (SPF 30), ethylhexyl methoxycinnamate and Tinosorb ${ }^{\circledR} S$ at the same concentration of LQFM048 (3), as standards.

\subsection{Toxicological Evaluation}

\subsubsection{Evaluation of Cytotoxicity of LQFM048 (3) on Balb/c 3T3 Cells}

2.10.1.1. Cell Culture. Balb/c 3T3-A31fibroblasts were cultured in Dullbecco's modified Eagle's medium (DMEM) supplemented with 10\% fetal bovine serum (FBS), $100 \mathrm{IU} / \mathrm{mL}$ penicillin and $100 \mathrm{mg} / \mathrm{mL}$ streptomycin, and routinely grown as a monolayer in $75 \mathrm{~cm}^{2}$ tissue culture flasks under standard culture conditions at $37{ }^{\circ} \mathrm{C}$ and $5 \% \mathrm{CO}_{2}$ in a humid environment. The cells were examined on a daily basis under a phase contrast microscope, and any changes in their morphology or adhesive properties were registered. Cell culture was removed from the culture flasks using trypsinization (trypsin/EDTA solution, $0.025 \%: 0.02 \%$ ) when the cells exceeded $50 \%$ confluence but before reaching $80 \%$ confluence [21].

2.10.1.2. Neutral Red Uptake (NRU) Assay. The NRU assay was performed according to the standard protocol of Borenfreund and Puerner [22] modified by NICEATM [23]. Briefly, Balb/c 3T3-A31 fibroblasts $\left(3 \times 10^{3}\right.$ cells/well $)$ were seeded in 96 -well plates, after $24 \mathrm{~h}$ the cells were treated with vehicle (DMSO 1\%) or eight different concentrations of LQFM048 (3) (4-490 $\mu \mathrm{M}$ ) in complete medium ( 6 wells per concentration) and incubated. The blank wells (with no cells) received complete culture medium with or without LQFM048 (3). After $48 \mathrm{~h}$, the solutions were removed from all plates and the cells were washed with $250 \mu \mathrm{L} /$ well of pre-warmed PBS. Posteriorly, $250 \mu \mathrm{L}$ of NR medium 
were added to all wells followed by incubation. After $3 \mathrm{~h}$, the NR medium was removed, the cells were carefully rinsed with $250 \mu \mathrm{L} /$ well of pre-warmed PBS and $100 \mu \mathrm{L}$ of NR desorb (50 ethanol: 1 acetic acid: 49 ultrapure water) solution were added to all wells. The plates were rapidly shaken on a microplate shaker for 20 min to extract NR from the cells and form a homogeneous solution. Absorbance was measured at $550 \mathrm{~nm}$ in a spectrophotometer. The optical density (OD) was calculated as the difference between absorbance at the test wavelength and that at the reference wavelength. For each concentration tested, wells containing all the reagents used but no cells served as reference blanks.

2.10.1.3. Lactate Dehydrogenase ( $L D H)$ Release Assay. Evaluation of LDH release was performed by in vitro toxicology assay kit, lactic dehydrogenase-based, (Sigma-Aldrich) as recommend by the manufacturer. Briefly, LDH assay mixture was previously prepared by mixing equal amounts of LDH assay substrate, cofactor and dye solutions. Aliquots of supernatant $(50 \mu \mathrm{L})$ from $3 \mathrm{~T} 3$-A31 cells $\left(3 \times 10^{3}\right.$ cells/well $)$ exposed to LQFM 048 (3) ( 245 or $490 \mu \mathrm{M})$ for $48 \mathrm{~h}$ were added to $100 \mu \mathrm{L}$ of assay mixture. The samples were incubated at room temperature for 30 min protected from light at a dark room. Absorbance was performed at 490 and $690 \mathrm{~nm}$ and the cell viability was calculated as described by Chan et al. [24].

\subsubsection{Evaluation of Acute Oral Toxicity of LQFM048 (3) in Mice}

2.10.1.4.1. Animal Care. Swiss male mice, weighing between 27 and $31 \mathrm{~g}$, were obtained from Indústria Química do Estado de Goiás IQUEGO (Goiânia, GO, Brazil). To ensure the welfare of mice, body weight loss, food/water consumption and changes in activity and behavior of the animals were daily checked as a clinical indication of animal suffering to determine when the animals had to be humanely sacrificed [25]. The animals were kept under constant environmental conditions with light-dark cycles and controlled temperature. Water and food were provided ad libitum. The experiments were carried out in accordance with institutional protocols and the guidelines of the Canadian Council on Animal Care [26]. All procedures and protocols (FUG no.137/2009) were reviewed and approved by the Research Ethics Committee of the Federal University of Goiás. At the end of each experiment, the animals were previously anesthetized with xylazine $(10 \mathrm{mg} / \mathrm{kg})$ and ketamine hydrochloride $(100 \mathrm{mg} / \mathrm{kg})$ administered intraperitoneally and then euthanized by cervical dislocation [25].

2.10.1.4.2. Acute Oral Systemic Toxicity. LQFM048 (3) acute oral toxicity evaluation was carried out according to OECD Guideline 423 - Acute Toxic Class Method [27]. In short, mice $(n=3)$ were randomly separated and doses of LQFM048 (3) diluted in sunflower oil were administered orally (gavage) in each animal (first dose of $0.3 \mathrm{~mL}$ and, after $3 \mathrm{~h}$, a second dose of $0.2 \mathrm{~mL}$ ). A single dose was not possible, because of the low solubility of LQFM048 (3) in oil, which would require the administration of a greater volume than recommended $(1 \mathrm{~mL} / 100 \mathrm{~g}$ of body weight on a single dose). Thus, the $2000 \mathrm{mg} / \mathrm{kg}$ dose was given in smaller fractions over a period not exceeding $24 \mathrm{~h}$. After treatment, clinical observations were conducted at 5, 15 and $30 \mathrm{~min}$, and each hour up to the twelfth hour of the first day. Posteriorly, the mice were examined once a day for an additional 13 days. The safety of $2000 \mathrm{mg} / \mathrm{kg}$ dose of LQFM048 (3) was subsequently confirmed in other mice as recommended by OECD guideline.

\subsection{Statistical Analysis}

All experiments were carried out in three independent experiments. Statistical analysis was performed using GraphPad Prism version 5.01 software for windows (San Diego, CA, USA) when necessary. The inter group variation was measured by one-way Analysis of Variance (ANOVA) followed by Bonferroni's test forcytotoxicity assays. Statistical significance was established as $\mathrm{p}<0.05$.

\section{Results and Discussion}

\subsection{Planning and Synthesis of LQFM048 (3)}

The design of a sunscreen compound with broad spectrum and molecular weight above $500 \mathrm{Da}$ [28] was based on the structure and chemical action of triazine (Tinosorb ${ }^{\circ} S$ and Univul T 150®) and (E)-ethyl 2cyano-3-(4hydroxy-3-methoxyphenyl)acrylate (2) sunscreens. Thus, LQFM048 (3) was originally designed from molecular hybridization strategy (Fig. 1).

Synthetic route of LQFM048 (Fig. 2) started with (E)-ethyl 2-cyano3-(4hydroxy-3-methoxyphenyl) acrylate (2) through Knoevenagel reaction [29], which was carried out through condensation of vanillin (4) and ethyl cyanoacetate (5), in water, using morpholine as catalyst. In this process, compound (2), 98\% yield, was obtained after an hour at room temperature [29]. It is noteworthy that compound (2) was patented in 2007 for use in sunscreen compositions containing a UVA sunscreen, photostabilizer and antioxidant [30]. Thus, it is clear that there are green approaches for carrying out organic reactions in water to prepare compounds of industrial interest. In turn, compound (3) was carried out through aromatic nucleofilic substitution between compound (2) and 2,4,6-trichloro-1,3,5-triazine (6), using $\mathrm{K}_{2} \mathrm{CO}_{3}$ as catalyst, have been obtained in $80 \%$ of yields. As shown in Fig. 2, the compound LQFM048 (3) was obtained in global yields of $80 \%$, after two steps from vanillin (1), a cheap and abundant natural product.

LQFM048 (3) has an organic UV filter profile due to its aromatic structure conjugated with a para electron-releasing and electronacceptor groups [31].

\subsection{Analysis of Antioxidant Potential of LQFM048 (3)}

As shown in Fig. 3, LQFM048 showed an interesting redox potential. The native electroactivity of (E)-ethyl 2-cyano-3-(4hydroxy-3methoxyphenyl)acrylate (2) is evidenced by anodic peak, $1 \mathrm{a}$, at peak potential, $E_{\mathrm{p} 1 \mathrm{a}}$, of $0.9 \mathrm{~V}$ observed for $\mathrm{MCP}-1$. In turn, the voltammetric profile observed for MCP-2 was similar to the one observed for carbon paste (CP) without any modification, being, thus, in agreement with the absence of electroactive groups. It could be also inferred that compound (2) may present higher antioxidant properties, but lower oxidative stability than compound (3).

Regarding DPPH• radical scavenging assay, the results showed no discoloration observed after time reaction, consequently suggesting that antioxidant activity of LQFM048 (3) by DPPH• was not detected at the concentrations tested (data not shown). LQFM048 (3) has no $\mathrm{OH}$ groups in its structural formula. Therefore, it is expected that this compound does not react with $\mathrm{DPPH} \bullet$, since phenol ionization is crucial in the reactions of phenols with DPPH• in solvents that can support ionization such as ethanol [32].

\subsection{Determination of the Thermogravimetric Curve of LQFM048 (3)}

The decomposition of LQFM048 (3) during its production could be excluded since the thermogravimetric curve shows that it is thermally stable up to temperatures around $250{ }^{\circ} \mathrm{C}$ (Fig. 4). The thermal decomposition occurs in two consecutive mass loss steps, as shown in DTG curve, with complete degradation of LQFM048 (3). Although compounds released by thermal degradation cannot be positively identified by TG, the association with the results of mass spectroscopy is reasonable. The first step occurs at the temperature range of $250-437{ }^{\circ} \mathrm{C}$ with $60.2 \%$ weight loss which can be assigned to the loss of the two of the three $\mathrm{C}_{13} \mathrm{H}_{12} \mathrm{NO}_{3}$ molecules present in the compound. A fragmentation pattern in the mass spectrum shows a peak relating to this molecular ion at $\mathrm{m} / \mathrm{z} 466$. The second step occurs at the temperature range of 437-600 ${ }^{\circ} \mathrm{C}$ with $39.8 \%$ weight loss which can be assigned to the loss of $\mathrm{C}_{13} \mathrm{H}_{12} \mathrm{NO}_{3}$ and $\mathrm{C}_{3} \mathrm{~N}_{3} \mathrm{O}_{3}$ molecules. In this case, the fragmentation observed at m/z 133 and m/z 126 may be associated with these units, 
Uvinul ${ }^{\circledR} \mathrm{T} 150(\mathbf{1})$

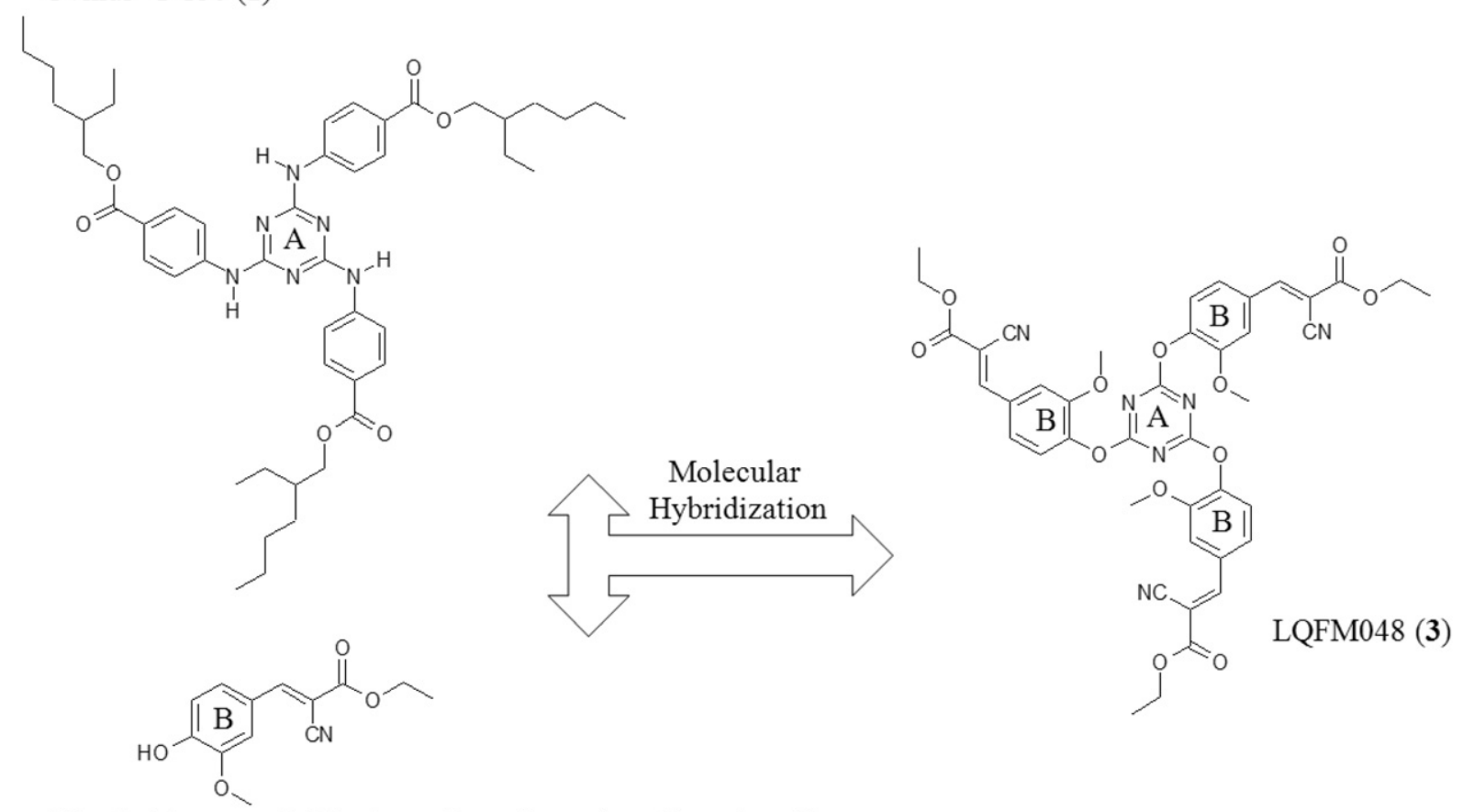

(E)-ethyl 2-cyano-3-(4hydroxy-3-methoxyphenyl)acrylate (2)

Fig. 1. Design of LQFM048 (3) from Uvinul ${ }^{\circledR}$ T 150 (1) and (E)-ethyl 2-cyano-3-(4hydroxy-3-methoxyphenyl)acrylate (2) sunscreens.

respectively. These results demonstrate that the LQFM048 (3) is stable against temperature rises, since its melting point is $186^{\circ} \mathrm{C}$.

\subsection{Photostability of LQFM048 (3) Upon Natural and Extreme Artificial Radiation}

Fig. 5a shows the photostability curve of LQFM048 (3) with or without sun exposure. It was observed that LQFM048 (3) showed a low degradation after $150 \mathrm{~min}$ of sunlight exposure at $39^{\circ} \mathrm{C}$, since its AUC was $0.71 \pm 0.01$. Forced photodegradation analysis of LQFM048 (3) was also carried out using a chamber with uniform light distribution and high intensity levels (Fig. 5a). As expected, the extreme radiation conditions induced a considerable photodegradation of LQFM048 (3), especially when irradiated by VIS and VIS + UVA. The AUC values were $0.40 \pm 0.13,0.73 \pm 0.01$ and $0.38 \pm 0.01$ for VIS, UVA and VIS + UVA, respectively. In these experimental conditions, it was possible to observe a decrease of LQFM048 (3) concentration with no photoproduct generation after natural and artificial exposure. The results found here highlight the need to include LQFM048 (3) in a future formulation with appropriate pharmaceutical adjuvants during the development stage of a sunscreen. This is an important pharmaceutical strategy to keep the photostability of sunscreens [33] and studies carried out in these complex mixtures are more relevant from the consumer's point of view [17].<smiles>COc1cc(C=O)ccc1O</smiles>

(4)

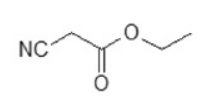

(5)

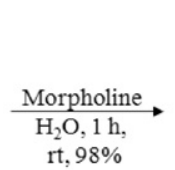<smiles>CCOC(=O)/C(C#N)=C/c1ccc(O)c(OC)c1</smiles>

(2)<smiles>CCOC(=O)C(C)=Cc1ccc(Oc2nc(Oc3ccc(C=C(C)C(=O)OCC)cc3OC)nc(Oc3ccc(C=C(C)C(=O)OCC)cc3OC)n2)c(OC)c1</smiles> 

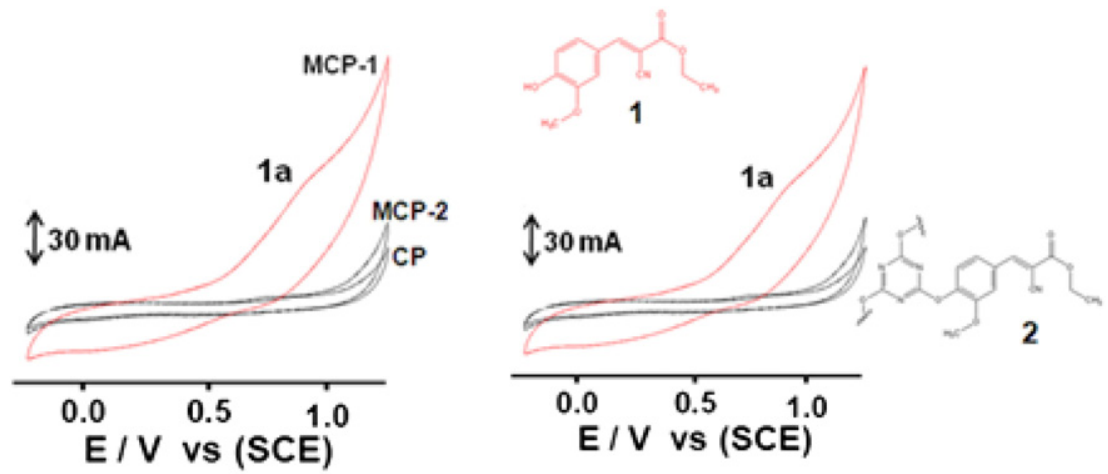

Fig. 3. Representative cyclic voltammograms obtained for MCP-1, MCP-2 and CP, in pH 7.0, $0.1 \mathrm{M}$ phosphate buffer. Scan rage from -0.25 to $1.25 \mathrm{~V}$, scan rate of $100 \mathrm{mV} \mathrm{s}^{-1}$.

\subsection{Photophysical Characterization of LQFM048 (3)}

Steady-state fluorescence emission and excitation spectra were obtained for LQFM048 (3) in chloroform, toluene, tetrahydrofuran (THF) and acetonitrile $(\mathrm{MeCN})$ solutions at distinct concentrations, from $10^{-6} \mathrm{~mol} \mathrm{~L}^{-1}$ to $10^{-4} \mathrm{~mol} \mathrm{~L}^{-1}$. In diluted solutions, maxima of excitation were at 290 and $345 \mathrm{~nm}$, regardless of the solvent used to produce the dilute solutions, while fluorescence emission was at the range of 310 to $520 \mathrm{~nm}$. These spectra demonstrated luminescence intensities and wavelengths depend on solvent identity, changing from $360 \mathrm{~nm}$ in acetonitrile to 420 in chloroform or toluene. Moreover, in THF maximum fluorescence is also at $420 \mathrm{~nm}$, but presenting a shoulder of half intensity at around $350 \mathrm{~nm}$. In general, fluorescence spectra obtained for these diluted solutions are structureless and excitation/emission spectral overlap is evident in all solutions. Excitation and fluorescence spectra are shown in Supplementary Figure 1.

The concentration effect upon excitation and fluorescence spectra of solutions prepared in these solvents was also evaluated. At higher concentrations, red-shifts of fluorescence spectra were observed for all solvents, along with a change in the excitation spectra shapes, which are related to electronic ground state aggregates formation. Nevertheless, in chloroform solutions, the behavior observed is opposite to that: at higher concentrations, fluorescence blue-shift is observed as result of electronic ground state aggregation. This may happen due to the fact that solubility of LQFM048 (3) compound is higher in chloroform than in the other chosen solvents, which causes electronic excited state stabilization with consequent destabilization of the electronic ground state, while aggregation gives rise to electronic energy transfer states, which

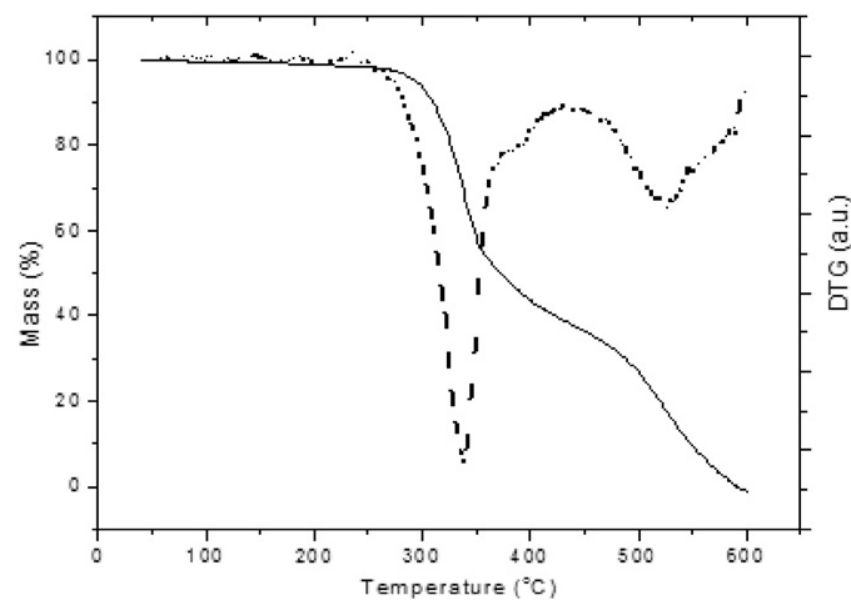

Fig. 4. Representative thermogravimetric analysis of LQFM048 (3). About $4.0 \mathrm{mg}$ of the compounds were heated under synthetic air atmosphere from 30 to $600{ }^{\circ} \mathrm{C}$, at a flow rate of $50 \mathrm{~mL} \mathrm{~min}{ }^{-1}$ and a heating rate of $10{ }^{\circ} \mathrm{C} / \mathrm{min}$. are formed at higher energy levels. This distinct behavior for distinct solvents is due to a balance of interactions involving strong dipole-dipole interactions and weak non-polar interactions that are modulated by specific characteristics of each solvent in the presence of LQFM048 (3), such as distinct refractive indexes $(\mathrm{n})$ and dielectric constants $(\varepsilon)$, which influence their polarizabilities $(\Delta \mathrm{f})$, as observed in Table 1 . Acetonitrile, which is the solvent with the highest polarizability, presents the lowest spectral shift, characterized by the small Stokes Shift value, while in toluene, the solvent with the lowest polarizability, characterized by the lowest dielectric constant and, hence, the smallest ability to electrostatically interact with the solute molecules.

Supplementary Figure 2 shows excitation and fluorescence spectra obtained for solutions in distinct solvents and concentrations. It is not clear, however, if the spectral behavior of chloroform solutions is related to specific interactions that may occur between LQFM048 (3) molecules and the solvent or if it is due to general electrostatic interaction forces that vary with solvent main characteristics. To better understand these shifts and associate them to general or specific solvent effects, LippertMataga treatment was carried out on the spectral responses obtained for LQFM048 (3) $10^{-6} \mathrm{~mol} \mathrm{~L}^{-1}$ solutions in chloroform, acetonitrile,

A

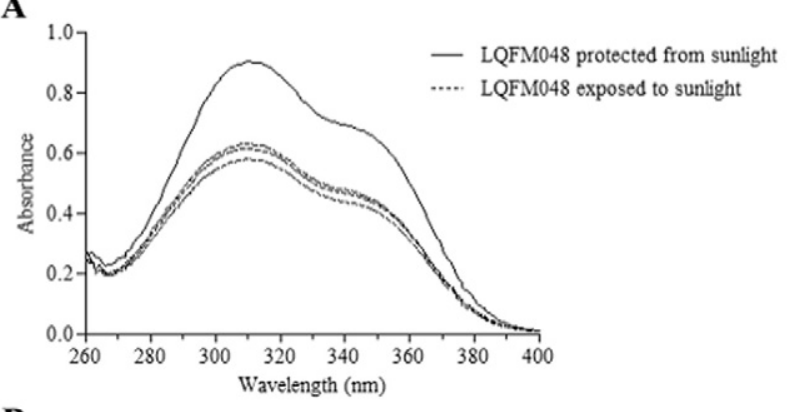

B

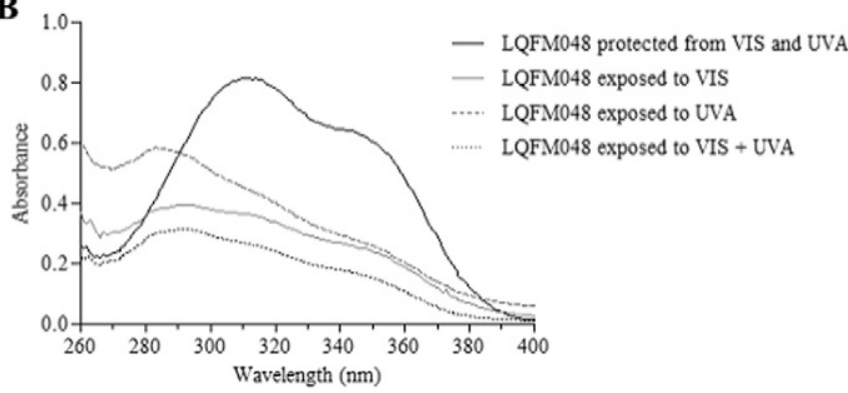

Fig. 5. Photostability of LQFM048 (3) upon natural and extreme artificial radiation. (A) The compound was exposed to natural sunlight at radiation dose of $54.2 \mathrm{~W} \cdot \mathrm{h} / \mathrm{m}^{2}$ for $150 \mathrm{~min}$ at $39{ }^{\circ} \mathrm{C} \pm 2$. (B) The LQFM048 (3) was exposed to UVA $\left(200 \mathrm{~W} \cdot \mathrm{h} / \mathrm{m}^{2}\right)$, VIS ( 1.2 million lux) and to both radiation under controlled temperature of $25{ }^{\circ} \mathrm{C}$, following recommendations of ICH Q1B, option 2. The figure shows a representative result in one of the three replicates. 
Table 1

Dielectric constants, refractive indexes, calculated polarizabilities of solvents used in this work and spectral Stokes shift obtained from excitation and fluorescence spectra of LQFM048 (3) diluted solutions.

\begin{tabular}{lrlll}
\hline Solvent & $\varepsilon$ & $\mathrm{n}$ & $\Delta \mathrm{f}$ & $\nu_{\mathrm{F}-} v_{\mathrm{A}}\left(\mathrm{cm}^{-1}\right)$ \\
\hline $\mathrm{C}_{7} \mathrm{H}_{8}$ & 2.38 & 1.492 & 0.0147 & 4511 \\
$\mathrm{CHCl}_{3}$ & 4.81 & 1.444 & 0.1489 & 4524 \\
$\mathrm{THF}$ & 7.58 & 1.407 & 0.2097 & 4349 \\
$\mathrm{MeCN}$ & 37.50 & 1.340 & 0.3067 & 2659 \\
\hline
\end{tabular}

toluene and tetrahydrofuran as solvents. At this concentration, good optical response was obtained with low aggregation occurrence. LippertMataga plot relates the Stokes shifts of excitation and fluorescence spectra to the polarizability of each solvent, hence, evidencing the nature of solute-solvent interactions. Lippert-Mataga plot is shown in Supplementary Figure 3.

This plot evidences a more important effect on the Stokes shift in solvents with lower polarizabilities, such as toluene, while as solvent polarizability becomes higher, the shift between excitation and fluorescence maxima becomes smaller, evidencing a more important spectral overlap in such solvents. Yet, since toluene is an aromatic solvent, solute-solvent non-polar interactions are important and they are based on $\pi$-stacking interaction, which might be the actual reason for the strong Stokes shift. Therefore, Lippert-Mataga treatment demonstrates the role that solute-solvent specific interactions play in the photophysical behavior of LQFM048 (3) are more significant than the general interactions.

As to obtain an efficient UV light absorber to be applied in sunscreen formulations, high Stokes shifts are desired. In this sense, to ensure high Stokes shifts and, therefore, more efficient separation between absorption in the UV region and energy release as light emitted in Visible region, the essential characteristics of formulation components must be taken into account. Specially, formulations that enable $\pi$-stacking interactions by interacting with LQFM048 (3) molecules by means of aromatic rings interactions are preferable. In fact, the nature of interactions between solute and solvent molecules is determinant to destabilize and/or stabilize the electronic ground and excited states of LQFM048 (3) molecules and knowing the Stokes shifts in each system enables us to understand the magnitude of these effects. For instance, if stabilization of electronic excited states is occurring, a bathochromic effect is observed and fluorescence spectrum is shifted to longer wavelengths, meaning a decrease in energy involved in the luminescent process. On the other hand, when destabilization is occurring, a hypsochromic effect is observed, therefore, fluorescence spectrum is shifted to shorter wavelengths. If interaction is not effective, excitation and fluorescence maxima are not shifted, resulting in more important spectral overlaps. To act as an efficient sunscreen, emission must occur at wavelengths displaced from UV region, hence, it is desirable that fluorescence emission occurs in a bathochromic way, at the visible region of the spectrum. Additional, optimized geometry of LQFM048 (3) is represented in Fig. 6.

\subsection{Determination of SPF of LQFM048 (3)}

Both methodologies used in this study are in vitro techniques, aiming to predict the effect of compound LQFM048 (3) in protecting the human skin from sunburn and other undesirable effects of the sun. Recent researches have demonstrated that the results obtained using them are similar to the results obtained in vivo assays [34]. According to the assay described by Mansur et al. [19], the SPF value was 4.58 while the ethylhexyl methoxycinnamate showed a SPF value of 2.79, corroborating the literature data [35]. Thus, LQFM048 (3) showed an increment of $64 \%$ in the photoprotection with regard to ethylhexyl metoxycinamate, an advantageous sunscreen due to its broad spectrum of action, cost and formulations stability [19]. When the compound (3) was assayed with the Optometrics SPF-290S analyzer, the SPF value obtained was 2.28. Its association with ethylhexyl metoxycinamate and

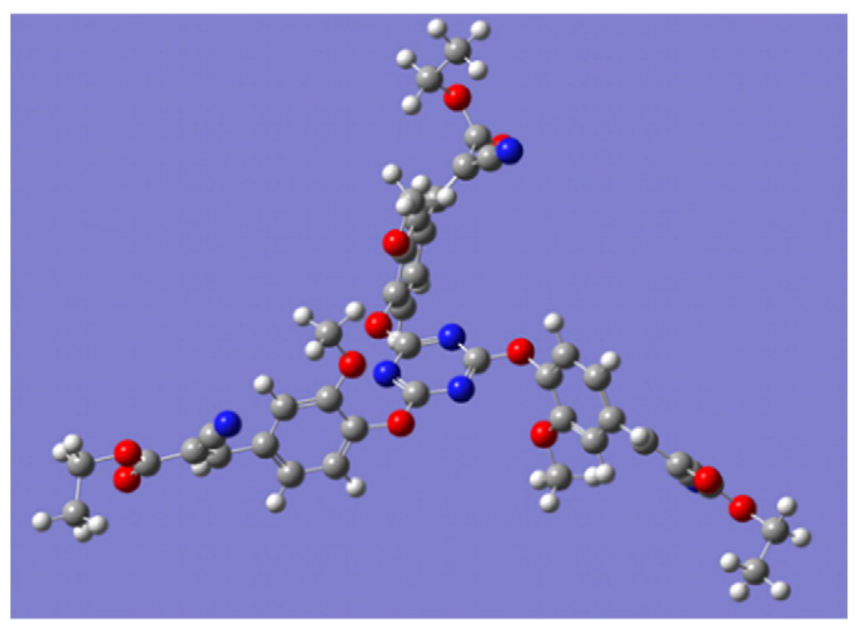

Fig. 6. Optimized geometry of LQFM048 (3).

Tinosorb® S obtained values of 13.94 and 22.44. In parallel, a commercial sunscreen (SPF 30) showed a value of 34.56 in our experimental conditions; while a new value of 40.52 was obtained when LQFM048 (3) was incorporated to this sunscreen product. According to our data, LQFM048 (3) presented good results of SPF and in association with other photoprotective compounds as well as with a commercial sunscreen.

\subsection{Evaluation of Cytotoxicity of LQFM048 (3) on Balb/c 3T3 Cells}

Basal cell viability assays provide the first information about the effect of unknown substances on cellular lethal endpoints and therefore may serve as suitable predictor for acute oral systemic toxicity [36]. Thus, 3T3 fibroblasts were exposed to eight different concentrations of LQFM048 (3) $(4-490 \mu \mathrm{M})$ and the basal cytotoxicity was evaluated by NRU assay. LQFM048 (3) promoted an increase of cell viability when compared to control, mainly on the first seven concentrations $(p<0.005)$ (Fig. 7a). This substance was not able to promote cytotoxicity for fibroblasts even to the highest concentrations ( 245 and $490 \mu \mathrm{M}$ ) that also showed a general morphology similar to the control group (Fig. 7b). Similar results, no cytotoxic profile of LQFM048 (3), were also found by the LDH release assay (Fig. 8).

\subsection{Acute Oral Systemic Toxicity Evaluation of LQFM048 (3) in Mice}

The dose selection for oral toxicity test was defined by the NRU results. Since there was very low cytotoxicity on 3T3-A31 cells, it was possible to estimate the starting dose for acute oral toxicity at $2000 \mathrm{mg} / \mathrm{kg}$. According to the guideline OECD 423, the first experiment using this dose produced no signs of toxicity or mortality in the animals during the 14 days of the study period. However, in the second experiment using $2000 \mathrm{mg} / \mathrm{kg}$ dose of LQFM048 (3), one death was observed on the day after the dosage of the animals. On both steps, no weight loss, alteration of consumption of water/food or macroscopic alteration in the organs of the other animals were detected (data not shown). Thus, according to the guideline OECD 423, LQFM048 (3) was classified at category 5 of Harmonized Classification System for Chemical Substances and Mixtures (GSH) and LD $_{50}$ (single dose that can promote death in $50 \%$ of animals when administered by oral route) determined as $2.000 \mathrm{mg} / \mathrm{kg}>\mathrm{LD}_{50}<5.000 \mathrm{mg} / \mathrm{kg}$. According to $\mathrm{OECD}$ [27], substances classified under category 5 are usually of relatively low acute toxicity hazard.

\section{Conclusions}

The new photoprotective compound LQFM048 (3) was obtained in high global yields using a green synthesis method and showed 
$\mathbf{A}$
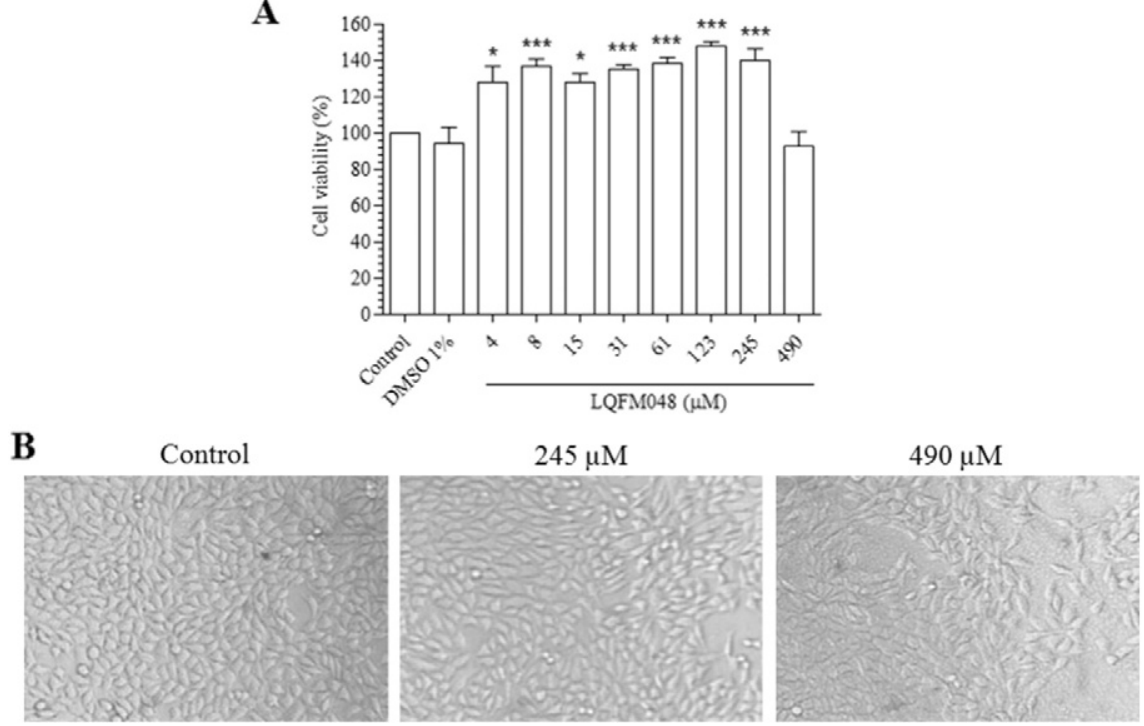

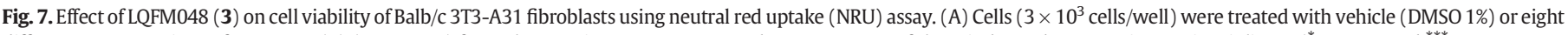

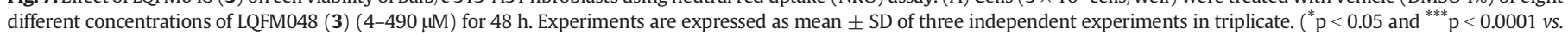
control. One way ANOVA and Bonferroni test). (B) General morphology of cells after treatment without or with the highest concentrations of LQFM048 (3) (245 and $490 \mu \mathrm{m})$.

thermally and oxidative stable. In addition, it has no cytotoxic effects on basal cells and showed low oral systemic acute toxicity. Therefore, this compound is promising as an alternative photoprotective compound with potential antioxidant properties. More studies are being accomplished to determine the safety and efficacy of this compound.

\section{Acknowledgments}

The authors acknowledge the Fundação de Apoio à Pesquisa - UFG (FUNAPE), Conselho Nacional de Desenvolvimento Científico e Tecnológico (CNPq), Financiadora de Estudos e Projetos (FINEP) and Coordenação de Aperfeiçoamento de Pessoal de Nível Superior (CAPES) for funding. The authors thank Angelo da Cunha Pinto (in memorian) from (Chemistry Institute, Federal University of Rio de Janeiro, RJ, Brazil) for the use of the mass spectroscopy.

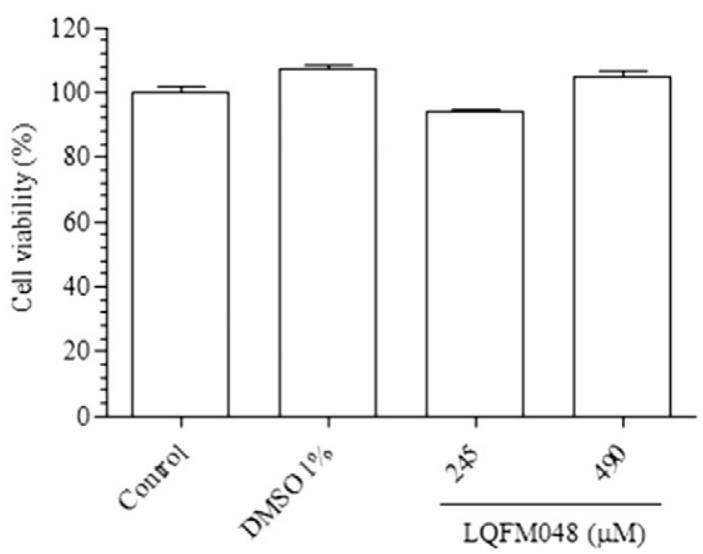

Fig. 8. Effect of LQFM048 (3) on cell viability of Balb/c 3T3-A31 fibroblasts using lactate dehydrogenase $(\mathrm{LDH})$ release assay. Cells $\left(3 \times 10^{3}\right.$ cells/well) were treated with vehicle (DMSO 1\%) or the highest concentrations of LQFM048 (3) (245 and $490 \mu \mathrm{m}$ ) for $48 \mathrm{~h}$. Experiments are expressed as mean \pm SD of three independent experiments in triplicate. (Data with no statistical difference. One way ANOVA and Bonferroni test).

\section{Appendix A. Supplementary data}

Supplementary data to this article can be found online at http://dx. doi.org/10.1016/j.jphotobiol.2016.03.042.

\section{References}

[1] H.-M. Chiang, H.-H. Chiu, S.-T. Liao, Y.-T. Chen, H.-C. Chang, K.-C. Wen, Isoflavonoidrich flemingia macrophylla extract attenuates UVB-Induced skin damage by scavenging reactive oxygen species and inhibiting MAP kinase and MMP expression, Evid. Based Complement. Alternat. Med. 2013 (2013).

[2] M.A. Serrano, J. Cañada, J.C. Moreno, G. Gurrea, Occupational UV exposure of environmental agents in Valencia, Spain. Photochem. Photobiol. 90 (2014) 911-918.

[3] C. Marionnet, C. Tricaud, F. Bernerd, Exposure to non-extreme solar UV daylight: spectral characterization, effects on skin and photoprotection, Int. J. Mol. Sci. 16 (2015) 68-90.

[4] S.Q. Wang, Y. Balagula, U. Osterwalder, Photoprotection: a review of the current and future technologies, Dermatol. Ther. 23 (2010) 31-47.

[5] L. Trémezaygues, J. Reichrath, From the bench to emerging new clinical concepts: our present understanding of the importance of the vitamin D endocrine system (VDES) for skin cancer, Dermatoendocrinol 3 (2011) 11-17.

[6] A. Tewari, R.P. Sarkany, A.R. Young, UVA1 induces cyclobutane pyrimidine dimers but not 6-4 photoproducts in human skin in vivo, J. Investig. Dermatol. 132 (2012) 394-400.

[7] M. Norval, G.M. Halliday, The consequences of UV-induced immunosuppression for human health, Photochem. Photobiol. 87 (2011) 965-977.

[8] G.P. Pfeifer, A. Besaratinia, UV wavelength-dependent DNA damage and human non-melanoma and melanoma skin cancer, Photochem. Photobiol. Sci. 11 (2012) 90-97.

[9] Y.J. Jiang, A.E. Teichert, F. Fong, Y. Oda, D.D. Bikle, $1 \alpha, 25(\mathrm{OH}) 2$-dihydroxyvitamin D3/VDR protects the skin from UVB-induced tumor formation by interacting with the $\beta$-catenin pathway, J. Steroid Biochem. Mol. Biol. 136 (2013) 229-232.

[10] N.J. Downs, A.V. Parisi, D. Igoe, Measurements of occupational ultraviolet exposure and the implications of timetabled yard duty for school teachers in Queensland, Australia: preliminary results, J. Photochem. Photobiol. B 131 (2014) 84-89.

[11] S. Kim, K. Choi, Occurrences, toxicities, and ecological risks of benzophenone-3, a common component of organic sunscreen products: a mini-review, Environ. Int. 70 (2014) 143-157.

[12] F.P. Gasparro, M. Mitchnick, J.F. Nash, A review of sunscreen safety and efficacy, Photochem. Photobiol. 68 (1998) 243-256.

[13] N.I. Chang, M. Yoo, S. Lee, Determination of fourteen sunscreen agents in cosmetics using high-performance liquid chromatography, Int. J. Cosmet. Sci. 37 (2015) $175-180$.

[14] T. Bunhu, A. Kindness, B.S. Martincigh, Determination of titanium dioxide in commercial sunscreens by inductively coupled plasma-optical emission spectrometry, Afr. J. Chem. 64 (2011) 139-143.

[15] A.W. Sobanska, J. Pyzowski, Quantification of sunscreen ethylhexyl triazone in topical skin-care products by normal-phase TLC/densitometry, Sci. World J. 2012 (2012). 
[16] T.O. Fernandes, R.I. Ávila, S.S. Moura, G.A. Ribeiro, M.C. Valadares, M.M.V. Naves, Campomanesia adamantium (Myrtaceae) fruits protect HepG2 cells against carbon tetrachloride-induced toxicity, Toxicol. Rep. 2 (2014) 184-193.

[17] S. Afonso, K. Horita, J.P.S. Silva, I.F. Almeida, M.H. Amaral, P.A. Lobão, P.C. Costa, M.S. Miranda, J.C.G.E. Silva, J.M.S. Lobo, Photodegradation of avobenzone: stabilization effect of antioxidants, J. Photochem. Photobiol. B 140 (2014) 36-40.

[18] ICH - European Medicines Agency - EMEA, Topic Q1B. photostability testing of new active substances and medicinal productsCPMP/ICH/279/95. 1998. http://www.ema.europa.eu/docs/en_GB/document_library/Scientific_guideline/2009/09/WC500002647. pdf. Accessed 20 Nov 2014.

[19] J.S. Mansur, M.N.R. Breder, M.C.D. Mansur, R.D. Azulay, Determinação do fator de proteção solar por espectrofotometria, An. Bras. Dermatol. 61 (1986) 121-124.

[20] B.L. Diffey, J. Robson, A new substrate to measure sunscreen protection factors throughout the ultraviolet spectrum, J. Soc. Cosmet. Chem. 40 (1989) 127-133.

[21] M.S. Vieira, V. de Oliveira, E.M. Lima, M.J. Kato, M.C. Valadares, In vitro basal cytotoxicity assay applied to estimate acute oral systemic toxicity of grandisin and its major metabolite, Exp. Toxicol. Pathol. 63 (2011) 505-510.

[22] E. Borenfreund, J. Puerner, A simple quantitative procedure using monolayer cultures for cytotoxicity assays (HTD/NR-90), J. Tissue Cult. Methods 9 (1984) 7-9.

[23] ICCVAM, Test Method Evaluation Report (TIMER): in vitro Cytotoxicity Test Methods for Estimating Starting Doses for Acute Oral Systemic Toxicity Test. NIH Publication No. 07-4519, Research triangle park, NC: National institute for environmental health sciences, 2006 (http://ntp.niehs.nih.gov/pubhealth/ evalatm/index.html. Acessed 22 Dez 2014).

[24] F.K. Chan, K. Moriwaki, M.J. Rosa, Detection of necrosis by release of lactate dehydrogenase activity, Methods Mol. Biol. 979 (2013) 65-70.

[25] R. Hubrecht, J. Kirkwood, The UFAW Handbook on the Care and Management of Laboratory and Other Research Animals, Wiley-Blackwell, England, 2010.

[26] E.D. Olfert, B.M. Cross, A.A. Mc William, Ottawa: Canadian Council on Animal Care, 1993.
[27] OECD (Organization for Economic Cooperation and Development), Acute oral toxicity: acute toxic class method. Guideline for the testing of chemicals, n.423, http:// ntp.niehs.nih.gov/iccvam/suppdocs/feddocs/oecd/oecd_gl423.pdf2001 Accessed 20 Nov 2014.

[28] C. Tuchinda, H.W. Lim, U. Osterwalder, A. Rougier, Novel emerging sunscreen technologies, Dermatol. Clin. 24 (2006) 105-117.

[29] M.N. Gomes, C.M.A. de Oliveira, C.F.D. Garrote, V. de Oliveira, R. Menegatti, Condensation of ethyl cyanoacetate with aromatic aldehydes in water, catalyzed by morpholine, Synth. Commun. 41 (2011) 52-57.

[30] R. Chaudhuri, Sunscreen compositions containing a UVA sunscreen and photostabilizers and antioxidants. MERCK U.S. Company. Patent no. 0059258. United States Patent, 2007.

[31] M.V.R. Velasco, F.D. Sarruf, I.M.N. Salgado-Santos, C.A. Haroutiounian-Filho, T.M Kaneko, A.R. Baby, Broad spectrum bioactive sunscreens, Int. J. Pharm. 363 (2008) 50-57.

[32] I. Gülçin, Antioxidant activity of food constituents: an overview, Arch. Toxicol. 86 (2012) 345-391.

[33] H. Gonzalez, N. Tarras-Wahlberg, B. Strömdahl, A. Juzeniene, J. Moan, O. Larkö, A Rosén, A. Wennberg, Photostability of commercial sunscreens upon sun exposure and irradiation by ultraviolet lamps, BMC Dermatol. 26 (2007) 1.

[34] P.J. Matts, V. Alard, M.W. Brown, L. Ferrero, H. Gers-Barlag, N. Issachar, D. Moyal, R. Wolber, The COLIPA in vitro UVA method: a standard and reproducible measure of sunscreen UVA protection, Int. J. Cosmet. Sci. 32 (2010) 35-46.

[35] The European Cosmetic Toiletry and Perfumery Association (COLIPA), Guideline of in vitro Method for the Determination of the UVA Protection Factor and "Critica Wavelength" Values of Sunscreen Products, 2009.

[36] U. Ukelis, P. Kramer, K. Olejniczak, S.O. Mueller, Replacement of in vivo acute ora toxicity studies by in vitro cytotoxicity methods: opportunities, limits and regulatory status, Regul. Toxicol. Pharmacol. 51 (2008) 108-118. 